\title{
Effects of preoperative exposure to a high-fat versus a low-fat diet on ingestive behavior after gastric bypass surgery in rats
}

\author{
Florian Seyfried • Alexander D. Miras • \\ Marco Bueter • Christina G. Prechtl • \\ Alan C. Spector · Carel W. le Roux
}

Received: 20 February 2013/Accepted: 10 May 2013/Published online: 30 May 2013

(C) Springer Science+Business Media New York 2013

\begin{abstract}
Background The consumption of high fat and sugar diets is decreased after gastric bypass surgery (GB). The mechanisms remain unclear, with tests of motivated behavior toward fat and sugar producing conflicting results in a rat model. These discrepancies may be due to differences in presurgical maintenance diets. The authors used their GB rat model to determine whether the fat content of preoperative maintenance diets affects weight loss, calorie intake, and macronutrient selection after surgery.

Methods Male Wistar rats were either low-fat diet fed (LFDF) with normal chow or high-fat diet fed (HFDF) before randomization to GB or sham surgery. In food preference test 1 , the animals were offered the choice of a vegetable drink (V8) or a high-calorie liquid (Ensure), and
\end{abstract}

Florian Seyfried and Alexander D. Miras contributed equally to this study.

F. Seyfried · A. D. Miras $(\bowtie) \cdot$ C. G. Prechtl · C. W. le Roux Investigative Science, Imperial College London, Du Cane Road, London W12 0NN, UK

e-mail: a.miras@nhs.net

\section{F. Seyfried}

Department of General and Visceral, Vascular and Paediatric

Surgery, University of Würzburg, Würzburg, Germany

\section{A. D. Miras}

Molecular and Metabolic Imaging Group, MRC Institute of Clinical Sciences, Imperial College London, Du Cane Road, London W12 0NN, UK

M. Bueter

Zurich Centre for Integrative Human Physiology, University

of Zurich, Zurich, Switzerland in food preference test 2, they could choose normal chow or a solid high-fat diet.

Results The GB groups did not differ significantly in terms of body weight loss or caloric intake. In food preference test 1 , both groups responded similarly by reducing their preference for Ensure and increasing their preference for V8. In food preference test 2, the HFDF-GB rats reduced their preference for a solid high-fat diet gradually compared with the immediate reduction observed in the LFDF-GB rats.

Conclusion The consumption of presurgical maintenance diets with different fat contents did not affect postoperative weight loss outcomes. Both the LFDF-GB and HFDF-GB rats exhibited behaviors consistent with the possible expression of a conditioned taste aversion to a high-fat stimulus. These results suggest that for some physiologic parameters, low-fat-induced obesity models can be used for the study of changes after GB and have relevance to many obese humans who consume high-calorie but low-fat diets.

\section{Bueter}

Department of Visceral and Transplant Surgery,

University Hospital Zurich, Zurich, Switzerland

\author{
A. C. Spector \\ Department of Psychology and Program in Neuroscience, \\ Florida State University, Tallahassee, FL, USA \\ C. W. le Roux \\ Experimental Pathology, School of Medicine and Medical \\ Science, Conway Institute, University College Dublin, Dublin, \\ Ireland
}


Keywords Aversion - Avoidance - Bariatric surgery · Food preferences - Taste

Gastric bypass surgery (GB) for morbid obesity has been shown to result in approximately $25 \%$ body weight loss over 20 years while also improving obesity-related comorbidities and mortality $[1,2]$. Reduction in food intake is a major factor contributing to the induction and maintenance of long-term body weight loss [3]. Increasing interest is focusing on changes in ingestive behavior and food selection, especially with respect to the dietary macronutrient composition that may occur after the GB and sleeve gastrectomy procedures [4-6].

The majority of the human literature on the changes in food preferences after GB suggests that patients consume fewer calories from energy-dense high fat and sugar foods and may even increase their consumption of fruits and vegetables [7-14]. However, the magnitude and durability of the reported GB-related changes in food selection show significant inconsistencies [4].

One potential source of the disparities in the literature may be the methodology used to assess intake (i.e. food diaries, dietary recall, and interviews, which are vulnerable to bias and inter- and intrasubject variability). Another possibility is that preoperative dietary habits may influence the nature of dietary shifts taking place after the operation, ultimately affecting the success of the procedure itself. In this regard, it is not known whether GB has differential effects on the two subgroups of patients most commonly encountered in the obesity clinic: the high-fat, high-sugar consumers and the high-volume low-fat, low-sugar consumers.

The use of rodent models of GB to investigate changes in food preference circumvents many caveats of human research while allowing more in-depth study of the responsible physiologic mechanisms. Indeed, the literature corroborates the conclusion that the consumption of highfat and high-sugar diets is decreased after GB [15-17]. The mechanisms behind this observation remain controversial, with tests of motivated behavior toward fat and sugar (e.g., the brief access test) producing opposing results when used by different investigators [18-20]. In a manner similar to the human situation, these discrepancies also may be due to differences in exposure to high-fat, high-sugar diets during the preoperative period. Indeed, most investigators render rats obese through high-fat feeding exclusively.

Although no consensus exists to date on the definition of diet-induced obesity in rats [21], its synonymity with highfat-diet-induced obesity first may have significant confounding effects on various tests used to assess feeding behavior and food selection after GB and second may not allow the translation of results to the clinical subpopulation of GB patients who are high-volume eaters but do not consume a diet abnormally high in fat. In this context, we used our established GB rat model [22] to determine whether the fat content of the preoperative maintenance diet affects weight loss, caloric intake, and selection of foods that differ in their macronutrient and energy content after surgery.

\section{Methods}

\section{Subjects}

In this study, 28 male Wistar rats (Harlan Laboratories, Oxon, UK) were housed under a 12/12-h light-dark cycle at room temperature $\left(21 \pm 2{ }^{\circ} \mathrm{C}\right)$. Water and standard laboratory chow (RM1 diet; Special Diet Services Ltd., Essex, UK; energy density, $3.5 \mathrm{kcal} / \mathrm{g}$; energy contribution from carbohydrates, $75.1 \%$; protein, $17.5 \%$; fat, $7.4 \%$ ) were available ad libitum, unless otherwise stated. All experiments were performed in accordance with UK Home Office regulations under the project license (PL 70/6669).

The experimental design is presented in Fig. 1. The 28 male Wistar rats (age 12-14 weeks) were divided into two groups based on their body weight. The low-fat-diet-fed (LFDF) group given normal chow included all the rats with a body weight above the median of $310.1 \mathrm{~g}$ (mean weight, $317.7 \pm 16.4 \mathrm{~g}$ ). These rats received ad libitum standard chow (LFDF).

The high-fat-diet-fed (HFDF) group included all the rats weighing less than a median of $310.1 \mathrm{~g}$ (mean weight $279.6 \pm 16.9 \mathrm{~g})$. These rats had free access to a solid highfat diet (C1090-60; Altromin GmbH \& Co. KG, Lage, Germany; energy density, $5.0 \mathrm{kcal} / \mathrm{g}$; energy contribution from carbohydrates, $19.8 \%$; protein, $17.7 \%$; fat, $62.5 \%$ ). This was done first to allow the two groups of rats to achieve the same body weight at the same age and at the same time before surgery and second to allow both groups to have sufficient exposure to the two diets.

Both groups stayed on their respective diets for 63 days. Between days -63 and -48 , the animals were housed two or three per cage, and body weight was recorded weekly. From day -14 onward, all the rats were kept singly housed, and both food intake and body weight were measured daily.

When the body weight of every rat exceeded $500 \mathrm{~g}$ and was in the obese range, the animals in both groups were randomized either to GB (10 LFDF-GB and 7 HFDF-GB) or sham procedure (6 LFDF-SH and 5 HFDF-SH). Postoperatively, all the animals were given a diet of normal chow powder mixed with water (wet diet) for 1 day. Thereafter, all the rats were offered standard normal chow ad libitum until postoperative day 15 . 


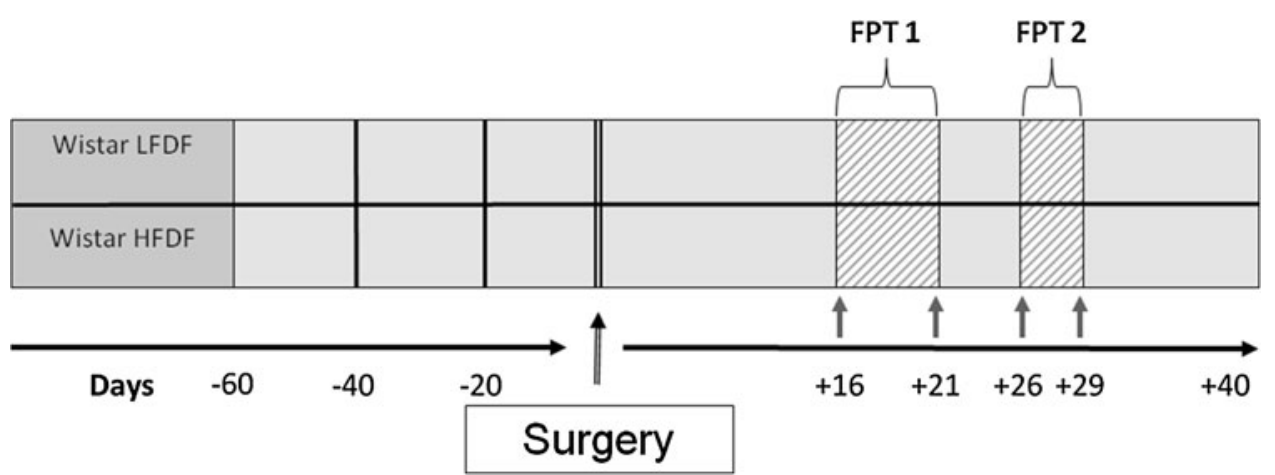

Fig. 1 Diagrammatic time line of the experimental design. The rats were either high-fat diet fed (HFDF) or low-fat diet fed (LFDF: normal chow) for 63 days before surgery. All the rats were offered normal chow between days 0 and 16 . In food preference test 1
(FPT 1), the rats were offered Ensure, V8, water, and $5 \mathrm{~g}$ of normal chow per day between postoperative days 15 and 21. In food preference test 2 (FPT 2), the rats were offered a solid high-fat diet, normal chow, and water between postoperative days 26 and 29

\section{Surgery}

All surgical procedures were performed by one surgeon (F.S.) as previously described [22]. Briefly, food was removed from the rats $6 \mathrm{~h}$ before surgery. Anesthesia was induced in a chamber with $5 \%$ isoflurane and $2 \%$ oxygen. The animals then were placed on a heating pad and given $1.25 \mathrm{mg} / \mathrm{kg}$ of amoxicillin intraperitoneally (IP) as a prophylactic antibiotic and $3 \mathrm{mg} / \mathrm{kg}$ of carprofen subcutaneously as an analgesia. Anesthesia was maintained with 2-3\% isoflurane and $2 \%$ oxygen.

The abdominal wall was opened through a midline incision. For the GB, the jejunum was transected $16 \mathrm{~cm}$ aboral to the pylorus to create the biliopancreatic limb. In the next step, the gastroesophageal junction was exposed, and the esophagus was mobilized. The left gastric vessels and vagal fibers were gently shifted laterally to avoid intraoperative bleeding and ischemia of the remnant stomach. The stomach then was divided $3 \mathrm{~mm}$ below the gastroesophageal junction to create a small pouch.

After closure of the gastric remnant, the aboral jejunum was anastomosed in an end-to-side fashion to the small pouch. The cecum then was identified, and a 7-mm side-toside jejunojejunostomy was made between the biliopancreatic limb and the alimentary limb, creating a common channel $25 \mathrm{~cm}$ long.

For the sham operations, the small bowel and the gastroesophageal junction were mobilized, and a gastrostomy $(1 \mathrm{~cm}$ long) was performed on the anterior wall of the stomach with subsequent closure. The abdominal wall was closed using continuous sutures, and the skin was closed intracutaneously. Buprenorphine $(0.1 \mathrm{~g} / \mathrm{kg} \mathrm{IP})$ was administered for postoperative analgesia during surgery and on postoperative days 1 and 2 once a day.

\section{Food preference tests}

The food preference test 1 took place between postoperative days 15 and 21. The animals were offered three different types of ad libitum liquids in three single bottles as follows: $450 \mathrm{ml}$ of water, $75 \mathrm{ml}$ of a commercially available vegetable drink (V8; Campbell Foods, Puurs, Belgium: energy density, $0.2 \mathrm{kcal} / \mathrm{g}$; energy contribution from carbohydrates, $67.2 \%$; protein, $21.3 \%$; fat, $12.5 \%$ ) and $150 \mathrm{ml}$ of a commercially available balanced high-calorie liquid diet equivalent to a mixed meal (Ensure; Abbot, Maidenhead, UK: energy density, $1.5 \mathrm{kcal} / \mathrm{g}$; energy contribution from carbohydrates, $54.5 \%$; protein, $15.0 \%$; fat, $30.5 \%$ ).

Each day, the contents of the bottles were freshly prepared and weighed at room temperature before they were given to the rats at the onset of the dark phase. The position of the bottles was swapped every $24 \mathrm{~h}$ to avoid the development of a preference for a specific bottle position.

To control for spillage, three additional bottles containing the same liquids were placed in an empty cage handled similarly to the cages containing the rats. The spillage was measured and subtracted from the consumed volumes of the rats before analysis.

Preference for V8 was expressed as a proportion of total fluid intake [V8/(V8 + Ensure + water intake)]. All the rats also were offered $5 \mathrm{~g}$ of normal chow to control for the effects of incisor growth. Between days 22 and 25, the rats received standard chow ad libitum before food preference test 2 was started.

In food preference test 2, between postoperative days 26 and 29 , the all rats were offered free access to both standard chow and a solid high-fat diet. From postoperative day 29 onward, all the rats were offered standard chow ad libitum. 
Statistical analysis

Two basic types of data analysis were conducted using Graph Pad Prism version 5. First, to discern the effect of surgical condition (SH vs. GB) on measures within the HFDF and LFDF groups, a two-way analysis of variance (ANOVA) (surgical condition vs. time in days) was performed for each dietary group. Second, to discern the effect of preoperative dietary condition (HFDF vs. LFDF) on measures within the GB and $\mathrm{SH}$ groups, a two-way ANOVA (diet $\times$ time in days) was performed for each surgical group. Finally, to discern the effect of each food preference test on measures within each of the four groups (before vs. during the food preference test), a two-way ANOVA (food preference test $\times$ time in days) was performed for each of the four groups.

\section{Results}

There was a mortality rate of $23.5 \%(4 / 17)$ after GB surgery, whereas none of the sham-treated animals died. In the LFDF group, 8 GB (LFDF-GB) and 6 sham-treated (LFDF$\mathrm{SH})$ animals completed both food preference tests, whereas in the HFDF group, 5 GB (HFDF-GB) and 5 sham-treated animals (HFDF-SH) completed both food preference tests.

\section{Body weight}

The plots showing the body weight of each group of rats are presented in Fig. 2. The HFDF and LFDF groups did not differ in body weight before surgery $(p=0.47)$. From the first few days after surgery, the body weight of the GB rats was significantly lower than that of the SH rats in both the HFDF and LFDF groups. Preoperative dietary exposure did not have a significant main effect on body weight in either the GB or SH groups (Table 1C).

Food preference test 1

Figure 3 illustrates the food intake and Fig. 4 the relative intake of V8 in all four groups during food preference test 1 on postoperative days 16-21. Table $1 \mathrm{~A}$ summarizes the results of food preference test 1 . Within both the HFDF and LFDF groups, surgery had a significant effect, with the GB rats showing a significantly lower intake of Ensure than the SH animals. Within both the GB and SH groups, the preoperative dietary exposure did not have a significant main effect on the intake of Ensure. The interaction of preoperative dietary exposure and time had a significant effect on the intake of Ensure only in the SH group.

Neither surgery nor preoperative dietary exposure had a significant effect on the absolute intake of V8. Intake of V8 also was expressed as a proportion of total fluid consumed [relative intake $=\mathrm{V} 8 /(\mathrm{V} 8+$ Ensure + water $)]$. Within both the HFDF and LFDF groups, surgery had a significant effect, with the relative V8 intake of the GB rats significantly higher than that of the SH rats.

Preoperative dietary exposure did not have a significant effect on the relative intake of V8 in either the GB or the SH group. Within both the HFDF and LFDF groups, surgery had a significant effect, with the GB rats consuming significantly fewer calories per day than the SH animals. Within both the GB and SH groups, preoperative dietary exposure had no significant main effect on daily caloric intake. The interaction of preoperative dietary exposure and time had a significant effect on daily caloric intake in both the GB and SH groups. The daily caloric intake of all four groups had stabilized by postoperative day 10 and was 20-30 \% lower in the GB group than in the SH group.

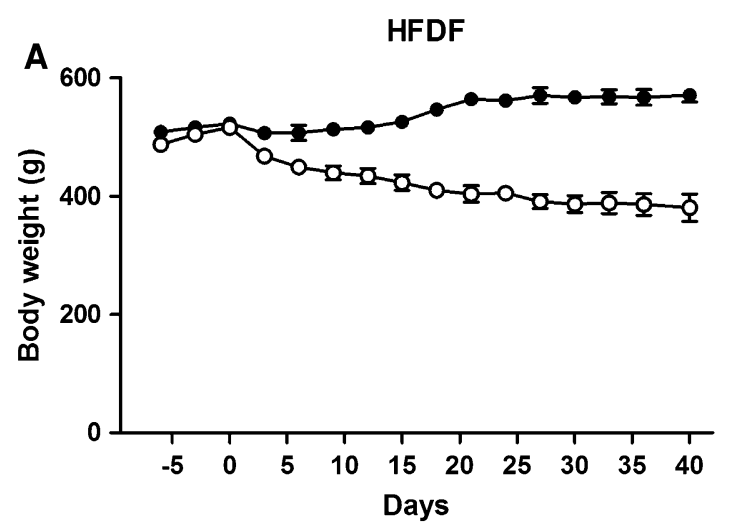

Fig. 2 Body weight plots of the A HFDF groups (HFDF-SH: $n=5$, filled circles, HFDF-GB: $n=5$, empty circles) and the B LFDF groups (LFDF-SH: $n=6$, filled squares, LFDF-GB: $n=8$, empty

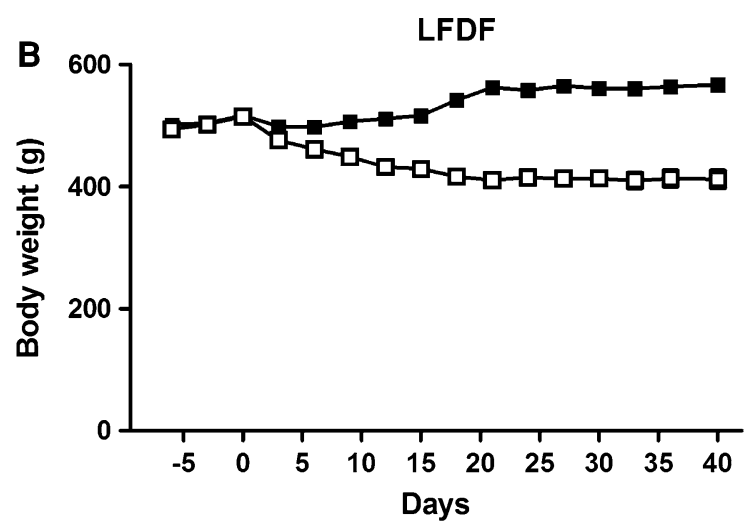

squares) throughout the study. Data are presented as mean \pm standard error of the mean. $H F D F$ high-fat diet fed, $L F D F$ low-fat diet fed, $S H$ sham procedure, $G B$ gastric bypass 
Table 1 Between-group comparisons

\begin{tabular}{|c|c|c|c|c|c|c|c|c|}
\hline & $\begin{array}{l}\text { HFDF-SH } \\
(n=5)\end{array}$ & $\begin{array}{l}\text { HFDF-GB } \\
(n=5)\end{array}$ & $\begin{array}{l}\text { LFDF-SH } \\
(n=6)\end{array}$ & $\begin{array}{l}\text { LFDF-GB } \\
(n=8)\end{array}$ & $\begin{array}{l}\text { HFDF group } \\
\text { Effect of } \\
\text { surgery } \\
\text { Effect of } \\
\text { time } \\
\text { Interaction }\end{array}$ & $\begin{array}{l}\text { LFDF group } \\
\text { Effect of } \\
\text { surgery } \\
\text { Effect of } \\
\text { time } \\
\text { Interaction }\end{array}$ & $\begin{array}{l}\text { GB group } \\
\text { Effect of } \\
\text { diet } \\
\text { Effect of } \\
\text { time } \\
\text { Interaction }\end{array}$ & $\begin{array}{l}\text { SH group } \\
\text { Effect of } \\
\text { diet } \\
\text { Effect of } \\
\text { time } \\
\text { Interaction }\end{array}$ \\
\hline \multicolumn{9}{|l|}{$A$} \\
\hline $\begin{array}{l}\text { Ensure intake } \\
\text { (g/day) }\end{array}$ & $99.6 \pm 3.7$ & $33.3 \pm 2.5$ & $107.6 \pm 2.8$ & $29.2 \pm 1.5$ & $\begin{array}{c}<0.0001 \\
0.0140 \\
0.23\end{array}$ & $\begin{array}{c}<0.0001 \\
0.39 \\
0.06\end{array}$ & $\begin{array}{l}0.49 \\
0.73 \\
0.07\end{array}$ & $\begin{array}{l}0.17 \\
0.13 \\
0.013\end{array}$ \\
\hline $\begin{array}{l}\text { V8 intake } \\
\text { (g/day) }\end{array}$ & $12.2 \pm 2.7$ & $12.3 \pm 2.6$ & $13.8 \pm 1.2$ & $15.9 \pm 2.1$ & $\begin{array}{l}0.98 \\
0.12 \\
0.91\end{array}$ & $\begin{array}{l}0.75 \\
0.24 \\
0.37\end{array}$ & $\begin{array}{l}0.63 \\
0.05 \\
0.85\end{array}$ & $\begin{array}{l}0.56 \\
0.16 \\
0.58\end{array}$ \\
\hline $\begin{array}{l}\text { V8 relative intake } \\
\text { (\%/day) }\end{array}$ & $10.0 \pm 1.7$ & $28.5 \pm 2.9$ & $11.3 \pm 0.9$ & $31.1 \pm 3.2$ & $\begin{array}{l}0.02 \\
0.38 \\
0.46\end{array}$ & $\begin{array}{l}0.013 \\
0.21 \\
0.28\end{array}$ & $\begin{array}{l}0.77 \\
0.31 \\
0.19\end{array}$ & $\begin{array}{l}0.51 \\
0.21 \\
0.78\end{array}$ \\
\hline $\begin{array}{l}\text { Caloric intake } \\
\text { (kcal/day) }\end{array}$ & $164.0 \pm 5.2$ & $70.3 \pm 4.2$ & $177.6 \pm 4.2$ & $64.6 \pm 1.9$ & $\begin{array}{c}<0.001 \\
0.028 \\
0.16\end{array}$ & $\begin{array}{c}<0.0001 \\
0.23 \\
0.03\end{array}$ & $\begin{array}{l}0.52 \\
0.41 \\
0.046\end{array}$ & $\begin{array}{l}0.14 \\
0.24 \\
0.004\end{array}$ \\
\hline$B$ & & & & & & & & \\
\hline $\begin{array}{l}\text { Solid high-fat diet } \\
\text { (g/day) }\end{array}$ & $15.3 \pm 1.4$ & $6.7 \pm 1.8$ & $17.6 \pm 0.5$ & $1.6 \pm 0.8$ & $\begin{array}{c}<0.0015 \\
<0.0001 \\
0.10\end{array}$ & $\begin{array}{c}<0.0001 \\
0.003 \\
0.50\end{array}$ & $\begin{array}{c}<0.0001 \\
<0.0001 \\
0.004\end{array}$ & $\begin{array}{l}0.33 \\
0.0009 \\
0.11\end{array}$ \\
\hline $\begin{array}{l}\text { Normal chow } \\
\text { (g/day) }\end{array}$ & $8.5 \pm 2.1$ & $12.4 \pm 3.1$ & $11.1 \pm 1.2$ & $24.6 \pm 2.0$ & $\begin{array}{c}0.27 \\
<0.0001 \\
0.31\end{array}$ & $\begin{array}{l}0.0001 \\
0.0005 \\
0.024\end{array}$ & $\begin{array}{c}0.002 \\
<0.0001 \\
0.16\end{array}$ & $\begin{array}{c}0.35 \\
<0.0001 \\
0.07\end{array}$ \\
\hline $\begin{array}{l}\text { Caloric intake } \\
\text { (kcal/day) }\end{array}$ & $106.6 \pm 1.7$ & $77.6 \pm 2.2$ & $127.5 \pm 2.0$ & $95.0 \pm 3.5$ & $\begin{array}{l}0.016 \\
0.63 \\
0.73\end{array}$ & $\begin{array}{l}0.0002 \\
0.60 \\
0.38\end{array}$ & $\begin{array}{l}0.045 \\
0.35 \\
0.77\end{array}$ & $\begin{array}{l}0.023 \\
0.42 \\
0.98\end{array}$ \\
\hline C & & & & & & & & \\
\hline Body weight (g) & $543.3 \pm 7.0$ & $420.1 \pm 10.3$ & $537.3 \pm 7.4$ & $432.9 \pm 8.4$ & $\begin{array}{l}<0.0001 \\
<0.0001 \\
<0.0001\end{array}$ & $\begin{array}{l}<0.0001 \\
<0.0001 \\
<0.0001\end{array}$ & $\begin{array}{c}0.38 \\
<0.0001 \\
0.15\end{array}$ & $\begin{array}{c}0.60 \\
<0.0001 \\
1.00\end{array}$ \\
\hline $\begin{array}{l}\text { Overall caloric intake } \\
\text { (kcal/day) }\end{array}$ & $102.1 \pm 5.0$ & $70.2 \pm 3.9$ & $110.3 \pm 5.5$ & $74.5 \pm 3.3$ & $\begin{array}{c}0.019 \\
<0.0001 \\
<0.0001\end{array}$ & $\begin{array}{l}<0.0001 \\
<0.0001 \\
<0.0001\end{array}$ & $\begin{array}{c}0.64 \\
<0.0001 \\
0.08\end{array}$ & $\begin{array}{c}0.06 \\
<0.0001 \\
0.01\end{array}$ \\
\hline
\end{tabular}

Data are presented as mean \pm standard error of the mean (SEM) or $p$ values. To discern the effect of surgical condition (SH vs. GB) on measures within the HFDF and LFDF groups, a two-way analysis of variance (ANOVA) (surgical condition vs. time in days) was performed for each dietary group. To discern the effect of presurgical dietary condition (HFDF vs. LFDF) on measures within the GB and SH groups, a two-way ANOVA (diet $\times$ time in days) was performed for each surgical group. The results for food preference test 1 are summarized in panel A, for food preference test 2 in panel B, and for experimental days 0 to 40 in panel C. Relative V8 intake is expressed as a proportion of total fluid intake $[\mathrm{V} 8 /(\mathrm{V} 8+$ Ensure + water intake) $]$

$H F D F$ high-fat diet fed, $S H$ sham procedure, $G B$ gastric bypass, $L F D F$ low-fat diet fed

Within-group comparisons of daily caloric intake during (postoperative days 16-21) versus before (postoperative days 10-15) food preference test 1 showed a significant increase in both the HFDF-SH and LFDF-SH groups, a trend for a decrease in the HFDF-GB group, and a significant decrease in the LFDF-GB group. Table 2 summarizes the within-group comparisons.

Figure 5 shows the daily calorie intake of all four groups from day 0 onward. Within both the HFDF and LFDF groups, surgery had a significant effect, with the GB rats 


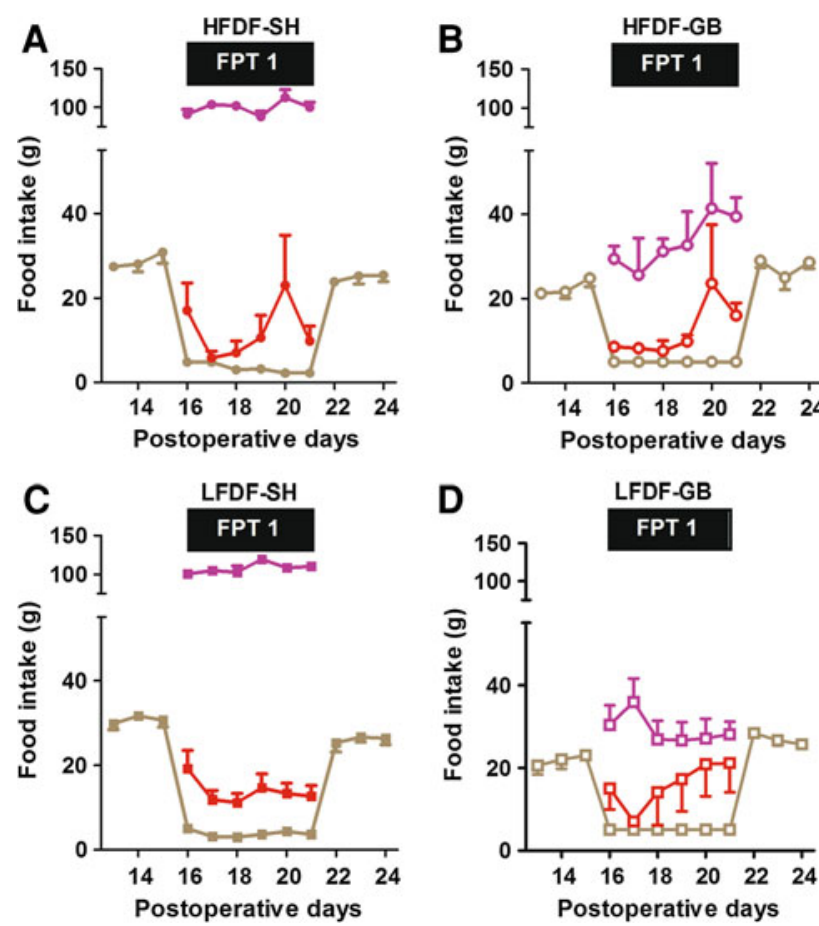

Fig. 3 Food intake of Ensure in purple, V8 in red, and normal chow in brown for the A HFDF-SH ( $n=5$, filled circles), B HFDF-GB ( $n=5$, empty circles), C LFDF-SH ( $n=6$, filled squares), and D LFDF-GB ( $n=8$, empty squares) groups during food preference test 1 (FPT 1), which took place between postoperative days 16 and 21. Data are presented as mean \pm standard error of the mean (SEM). $H F D F$ high-fat diet fed, $L F D F$ low-fat diet fed, $S H$ sham procedure, $G B$ gastric bypass (Color figure online)
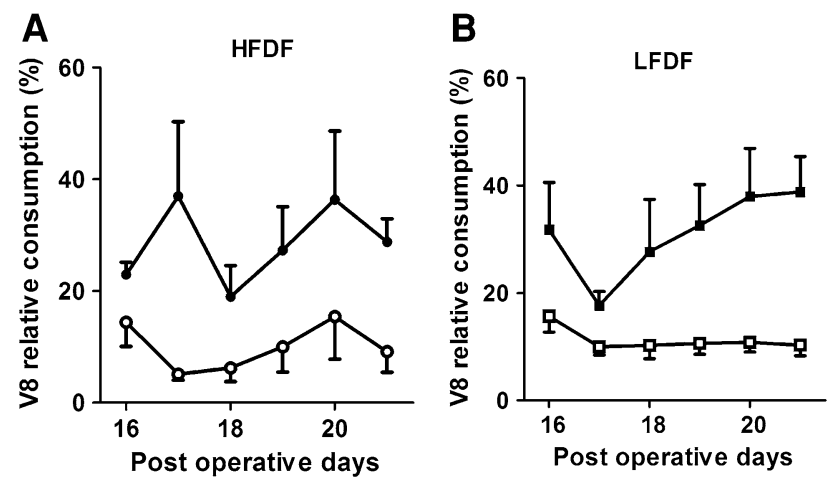

Fig. 4 Relative V8 consumption (relative intake $=$ V8/V8 + Ensure + water) for the A HFDF groups (HFDF-SH: $n=5$, filled circles, HFDF-GB: $n=5$, empty circles) and $\mathbf{B}$ LFDF groups (LFDFSH: $n=6$, filled squares, LFDF-GB: $n=8$, empty squares) during food preference test 1 , which took place between postoperative days 16 and 21. Data are presented as mean \pm standard error of the mean (SEM). HFDF high-fat diet fed, $L F D F$ low-fat diet fed, $S H$ sham procedure, $G B$ gastric bypass

showing a significantly lower daily caloric intake than the SH animals. Within both the GB and SH groups, preoperative dietary exposure had no significant main effect on the daily caloric intake. The interaction of preoperative dietary exposure and time had a significant effect only in the SH group (Table 1C).

Food preference test 2

Figure 6 demonstrates the food intake of all four groups during food preference test 2 , which took place on postoperative days 26-29. Table 1B summarizes the results of food preference test 2. Within both the HFDF and LFDF groups, surgery had a significant effect, with the GB rats showing a significantly lower intake of solid high-fat diet than the SH animals. Within the GB group, preoperative dietary exposure had a significant effect, with the rats exposed to LFDF preoperatively consuming significantly less solid high-fat diet than the rats exposed to HFDF preoperatively. Preoperative dietary exposure did not have an effect on solid high-fat intake in the SH group.

Surgery did have a significant effect on normal chow consumption in the LFDF group but not in the HFDF group because the GB rats in the LFDF group consumed significantly more normal chow than the SH rats. Preoperative dietary exposure had a significant effect on normal chow consumption in the GB group but not in the SH group because the GB rats exposed to LFDF preoperatively consumed significantly more normal chow than the rats exposed to HFDF preoperatively.

In both the HFDF and LFDF groups, surgery had a significant effect, with the GB rats consuming significantly fewer calories per day than the SH animals. In both the GB and SH groups, preoperative dietary exposure had a significant main effect on daily caloric intake, with the intake higher in the animals exposed to LFDF than in those exposed to HFDF preoperatively.

Within-group comparisons of daily caloric consumption during (postoperative days 26-29) versus before (postoperative days 22-25) food preference test 2 showed that it increased significantly in both the HFDF-SH and LFDF-SH groups, decreased significantly in the HFDF-GB group, and did not change in the LFDF-GB group (Table 2; Fig. 5).

\section{Discussion}

As the findings show, preoperative exposure to diets that differ in their fat content did not cause differences in weight loss but did cause subtle changes in ingestive behavior after GB surgery. The results of food preference test 1 suggest that GB led to the reduced consumption of a liquid diet high in fat and sugar content and that preoperative exposure to different diets did not have an effect on this change in ingestive behavior. In particular, the V8 findings were novel and in line with some of the studies from the human literature in which patients after GB 
Table 2 Within-group comparisons for food preference tests 1 and 2

\begin{tabular}{|c|c|c|c|c|c|}
\hline Group & $\begin{array}{l}\text { Caloric intake before food } \\
\text { preference test (kcal/day) }\end{array}$ & $\begin{array}{l}\text { Caloric intake during food } \\
\text { preference test (kcal/day) }\end{array}$ & $\begin{array}{l}\text { Effect of food } \\
\text { preference test } \\
(p \text { value })\end{array}$ & $\begin{array}{l}\text { Effect of time } \\
(p \text { value })\end{array}$ & $\begin{array}{l}\text { Interaction }(\text { food } \\
\text { preference test } \times \text { time }) \\
(p \text { value })\end{array}$ \\
\hline \multicolumn{6}{|c|}{ Food preference test 1} \\
\hline HFDF-SH $(n=5)$ & $97.6 \pm 2.5$ & $164.0 \pm 5.2$ & $<0.0001$ & 0.41 & 0.11 \\
\hline HFDF-GB $(n=5)$ & $77.3 \pm 2.6$ & $70.3 \pm 4.2$ & 0.054 & 0.58 & 0.26 \\
\hline LFDF-SH $(n=6)$ & $107.0 \pm 2.2$ & $177.6 \pm 4.2$ & $<0.0001$ & 0.32 & 0.03 \\
\hline LFDF-GB $(n=8)$ & $75.0 \pm 1.6$ & $64.6 \pm 1.9$ & 0.022 & 0.79 & 0.91 \\
\hline \multicolumn{6}{|c|}{ Food preference test 2} \\
\hline HFDF-SH $(n=5)$ & $86.9 \pm 1.5$ & $106.6 \pm 1.7$ & $<0.0001$ & 0.92 & 0.60 \\
\hline HFDF-GB $(n=5)$ & $96.6 \pm 3.6$ & $77.6 \pm 2.2$ & 0.0004 & 0.89 & 0.34 \\
\hline LFDF-SH $(n=6)$ & $90.3 \pm 2.4$ & $127.5 \pm 2.0$ & $<0.0001$ & 0.98 & 0.73 \\
\hline LFDF-GB $(n=8)$ & $93.0 \pm 2.9$ & $95.0 \pm 3.5$ & 0.63 & 0.44 & 0.15 \\
\hline
\end{tabular}

Data are presented as mean \pm standard error of the mean (SEM). To discern the effect of each food preference test on measures within each of the four groups (before vs. during the food preference test), a two-way analysis of variance (ANOVA) (food preference test $\times$ time in days) was performed for each of the four groups. The post hoc comparisons for time are not shown for simplicity and relevance

$H F D F$ high-fat diet fed, $S H$ sham procedure, $G B$ gastric bypass, $L F D F$ low-fat diet fed

increased their preference for fruits and vegetables [14]. Intake of V8 was unaffected by diet or GB, but because of the overall reduction in the total grams of fluid consumed, a two- to threefold increase in the relative intake of V8 was observed in the GB rats but not in the SH rats of both the LFDF and HFDF groups. The relative increase in V8 may have represented an attempt of the GB rats to obtain more calories.

We limited the duration of food preference test 1 to only 6 days because our pilot studies indicated that GB rats continued to increase their V8 intake, but this was not sufficient to compensate for the caloric deficit, even after normal chow was offered at $5 \mathrm{~g}$ per day. In fact, the GB rats from both groups also consumed all $5 \mathrm{~g}$ of normal chow available every day, whereas the $\mathrm{SH}$ rats in both groups did not consume all of it. Consequently, the GB rats started losing a significant amount of weight, and we did not want to reach a point at which their health was in jeopardy. We were surprised to observe that when the GB rats were exposed to the calorically dense Ensure, they avoided it to such a degree that their total caloric intake was reduced, resulting in additional weight loss. It also is interesting to note that both GB groups increased their food intake immediately after food preference test 1 to compensate for this weight loss during the test. This illustrates the absence of a surgically induced restrictive component because the rats were able to increase both the mass of food (normal chow) consumed and their caloric intake when physiologically required to do so.

The only difference in the ingestive behavior between the two groups of GB rats was observed in food preference test 2. Although the intake of a solid high-fat diet was significantly lower among the GB rats than among the SH rats in both the HFDF and LFDF groups, the LFDF-GB rats showed an immediate avoidance of the high-fat solid food, consistent with the rapid formation of a conditioned taste aversion to a novel stimulus. The HFDF-GB rats reduced their intake of the solid high-fat food gradually over 4 days, perhaps because the acquisition of a conditioned taste aversion was retarded due to familiarity of the stimulus as a function of their exposure to it during the preoperative period (e.g., [23]). In line with this, the amount of total calories consumed was reduced only in the HFDF-GB group. The amount of total calories consumed remained unchanged in the LFDF-GB rats because they avoided the high-fat diet immediately and continued to consume the same low-fat diet as before food preference test 2 .

The ability for lipid stimuli to serve as an effective unconditioned stimulus supporting the acquisition of a taste aversion in GB rats has been documented [17] but not universally observed [6]. It would be instructive for future work to examine the evolution of the HFDF avoidance in the LFDF-GB rats by performing a feeding pattern analysis. In addition, an analysis of oromotor taste reactivity in response to fat stimuli in GB rats before and after exposure to a novel high-fat diet would provide further insight. Indeed, it is possible that the acquisition of rapid aversions to at least fluid-based lipid stimuli could be assessed as the rats are being conditioned (e.g. [23]).

We did not examine the underlying mechanisms that may explain the changes in food preferences, but the paradigm we have established may now allow the examination of whether the increased consumption of the low-calorie vegetable drink was due to an increase in its taste-related reward value or to other postingestive factors. The limitations of this study also include the nonrandomized nature 

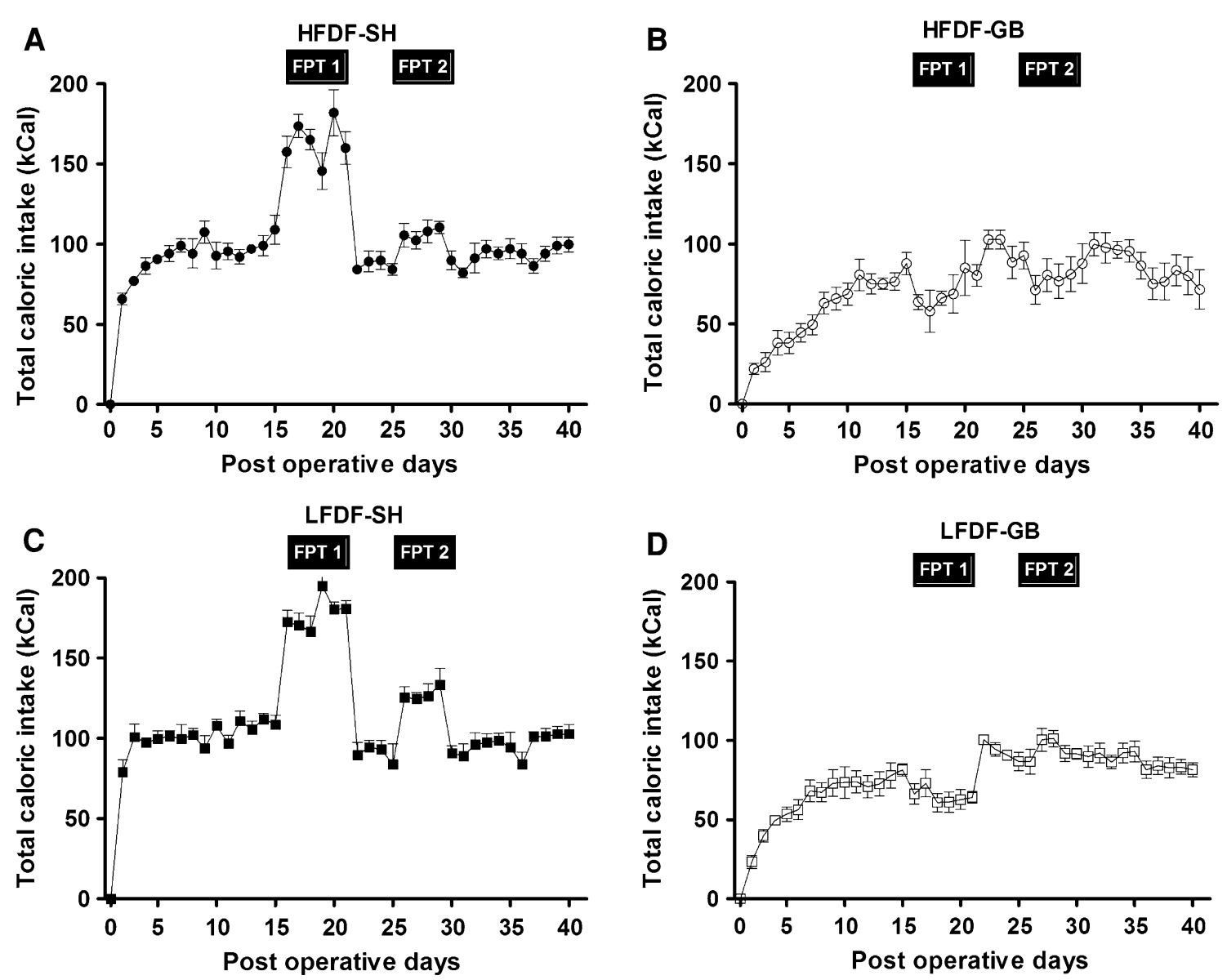

Fig. 5 Total calorie intake from postoperative day 10 until the end of the study for the A HFDF-SH ( $n=5$, filled circles), B HFDF-GB ( $n=5$, empty circles), C LFDF-SH ( $n=6$, filled squares), and D LFDF-GB ( $n=8$, empty squares) groups. Data are presented as

of the group allocation to normal chow or a high-fat diet before surgery. This was unavoidable due to our study design, which allowed us to control for the confounders of age and weight differences between groups.

We were reassured by the observation that the LFDFGB rats (with weights above the median when they were randomized to LFDF or HFDF) had an immediate reduction in consumption of solid high-fat chow in food preference test 2 , suggesting that the impact of the surgery and the preintervention chow were dominant compared with the possibility that the behavior of the rats was influenced by their proneness to obesity. We cannot exclude the possibility that the texture differences between the diets or nutrient malabsorption may have influenced the food preference observed in this set of experiments. However, no malabsorption was detected previously in our established rat model of GB [24].

Reassuringly, our findings are consistent with the results of the only other published study that used a similar paradigm [15]. In that experiment, a "lean" group of rats fed normal chow preoperatively lost substantial amounts of

mean \pm standard error of the mean (SEM). $H F D F$ high-fat diet fed, $L F D F$ low-fat diet fed, $S H$ sham procedure, $G B$ gastric bypass, FPT 1 food preference test $1, F P T 2$ food preference test 2

weight and showed a pattern of avoiding a high-fat diet after GB similar to the obese rats fed a high-fat diet. In our study, the contrast was not between lean and obese rats but between rats of equal weight fed different preoperative diets.

In conclusion, the consumption of preoperative maintenance diets with different fat contents did not affect postsurgical weight loss. Although the trends in feeding behavior were in the same direction for both GB groups, it took longer for the rats exposed to high-fat diets preoperatively to change their preference away from a high-fat diet to normal chow postoperatively. The preference of vegetable-based liquids (as a percentage of total volume of fluid consumed) increased in the GB rats independently of preoperative dietary exposure.

The aforementioned findings are consistent with studies investigating humans after GB but not with other bariatric procedures, in which reduced fat and increased vegetable intake probably resulted not only because patients were instructed to adopt these dietary choices but also because altered physiologic mechanisms after surgery promoted 

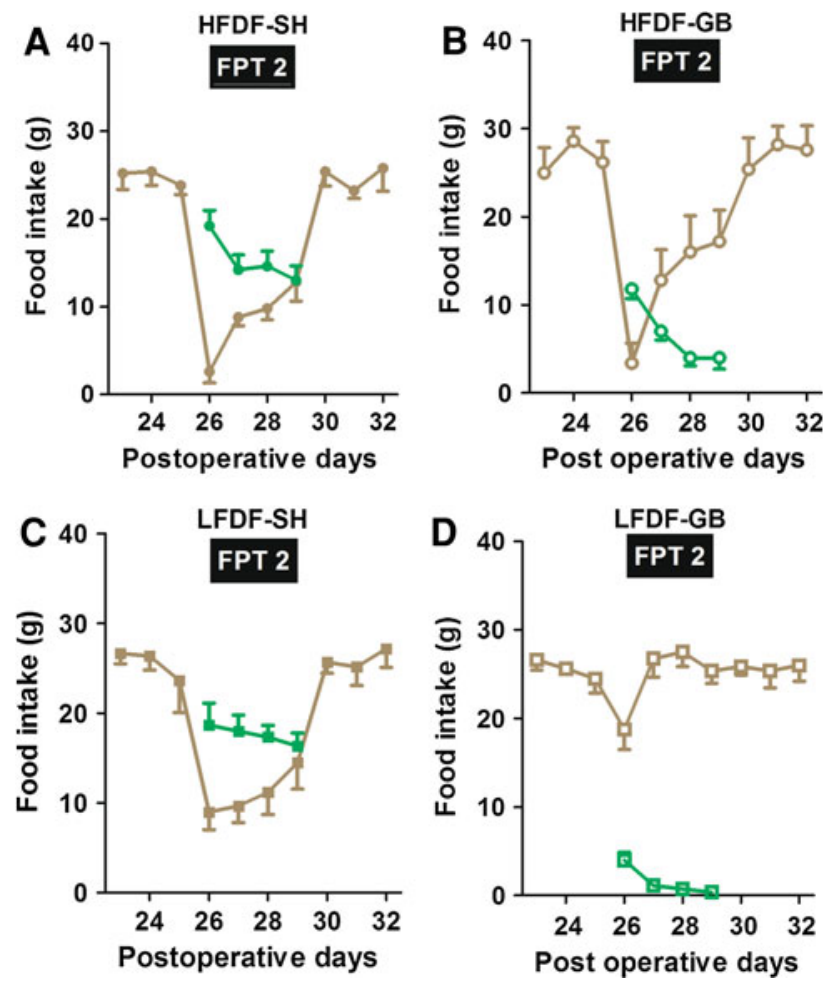

Fig. 6 Food intake of a solid high-fat diet in green and normal chow in brown for the A HFDF-SH ( $n=5$, filled circles $)$, B HFDF-GB ( $n=5$, empty circles), C LFDF-SH ( $n=6$, filled squares $)$, D LFDFGB ( $n=8$, empty squares) groups during food preference test 2 (FPT 2), which took place between postoperative days 26 and 29. Data are presented as mean \pm standard error of the mean (SEM). HFDF highfat diet fed, $L F D F$ low-fat diet fed, $S H$ sham procedure, $G B$ gastric bypass (Color figure online)

them [7-14]. An in-depth study of the mechanisms underlying the changes in food preference after GB could provide the opportunity not only to optimize our current surgical therapies but also to mimic them with effective and safer nonsurgical weight loss strategies.

Acknowledgments The financial support by the Deutsche Forschungsgemeinschaft (Florian Seyfried, SE 2027/1-1) and the National Institute on Deafness and Other Communication Disorders, National Institutes of Health, USA (R21-DC012751) is gratefully acknowledged.

Disclosures Alexander D. Miras was funded by the Medical Research Council Research Training Fellowship G0902002. Carel W. le Roux was supported by a Department of Health Clinician Scientist award. Imperial College London receives support from the NIHR Biomedical Research Centre funding scheme. Florian Seyfried, Alexander D. Miras, Marco Bueter, Christina G. Prechtl, Alan C. Spector, and Carel W. le Roux have no conflicts of interest or financial ties to disclose in relevance to this work.

\section{References}

1. Sjostrom L, Narbro K, Sjostrom CD, Karason K, Larsson B, Wedel H, Lystig T, Sullivan M, Bouchard C, Carlsson B, Bengtsson C, Dahlgren S, Gummesson A, Jacobson P, Karlsson J,
Lindroos AK, Lonroth H, Naslund I, Olbers T, Stenlof K, Torgerson J, Agren G, Carlsson LM (2007) Effects of bariatric surgery on mortality in Swedish obese subjects. N Engl J Med 357:741-752

2. Sjostrom L, Peltonen M, Jacobson P, Sjostrom CD, Karason K, Wedel $\mathrm{H}$, Ahlin S, Anveden A, Bengtsson C, Bergmark G, Bouchard C, Carlsson B, Dahlgren S, Karlsson J, Lindroos AK, Lonroth H, Narbro K, Naslund I, Olbers T, Svensson PA, Carlsson LM (2012) Bariatric surgery and long-term cardiovascular events. JAMA 307:56-65

3. Borg CM, le Roux CW, Ghatei MA, Bloom SR, Patel AG, Aylwin SJ (2006) Progressive rise in gut hormone levels after Roux-en-Y gastric bypass suggests gut adaptation and explains altered satiety. Br J Surg 93:210-215

4. Mathes CM, Spector AC (2012) Food selection and taste changes in humans after Roux-en-Y gastric bypass surgery: a directmeasures approach. Physiol Behav 107(4):476-483

5. Shin AC, Berthoud HR (2011) Food reward functions as affected by obesity and bariatric surgery. Int $\mathrm{J}$ Obes Lond 35(Suppl 3):S40-S44

6. Wilson-Perez HE, Chambers AP, Sandoval DA, Stefater MA, Woods SC, Benoit SC, Seeley RJ (2013) The effect of vertical sleeve gastrectomy on food choice in rats. Int $\mathrm{J}$ Obes Lond 37(2):288-295

7. Trostler N, Mann A, Zilberbush N, Charuzi II, Avinoach E (1995) Nutrient intake following vertical banded gastroplasty or gastric bypass. Obes Surg 5:403-410

8. Brown EK, Settle EA, Van Rij AM (1982) Food intake patterns of gastric bypass patients. J Am Diet Assoc 80:437-443

9. Kenler HA, Brolin RE, Cody RP (1990) Changes in eating behavior after horizontal gastroplasty and Roux-en-Y gastric bypass. Am J Clin Nutr 52:87-92

10. Coughlin K, Bell RM, Bivins BA, Wrobel S, Griffen WO Jr (1983) Preoperative and postoperative assessment of nutrient intakes in patients who have undergone gastric bypass surgery. Arch Surg 118:813-816

11. Brolin RL, Robertson LB, Kenler HA, Cody RP (1994) Weight loss and dietary intake after vertical banded gastroplasty and Roux-en-Y gastric bypass. Ann Surg 220:782-790

12. Kruseman M, Leimgruber A, Zumbach F, Golay A (2010) Dietary, weight, and psychological changes among patients with obesity, 8 years after gastric bypass. J Am Diet Assoc 110:527-534

13. Bavaresco M, Paganini S, Lima TP, Salgado W Jr, Ceneviva R, Dos Santos JE, Nonino-Borges CB (2010) Nutritional course of patients submitted to bariatric surgery. Obes Surg 20:716-721

14. Olbers T, Bjorkman S, Lindroos A, Maleckas A, Lonn L, Sjostrom L, Lonroth H (2006) Body composition, dietary intake, and energy expenditure after laparoscopic Roux-en-Y gastric bypass and laparoscopic vertical banded gastroplasty: a randomized clinical trial. Ann Surg 244:715-722

15. Zheng H, Shin AC, Lenard NR, Townsend RL, Patterson LM, Sigalet DL, Berthoud HR (2009) Meal patterns, satiety, and food choice in a rat model of Roux-en-Y gastric bypass surgery. Am J Physiol Regul Integr Comp Physiol 297:R1273-R1282

16. Bueter M, Miras AD, Chichger H, Fenske W, Ghatei MA, Bloom SR, Unwin RJ, Lutz TA, Spector AC, le Roux CW (2011) Alterations of sucrose preference after Roux-en-Y gastric bypass. Physiol Behav 104:709-721

17. le Roux CW, Bueter M, Theis N, Werling M, Ashrafian H, Lowenstein C, Athanasiou T, Bloom SR, Spector AC, Olbers T, Lutz TA (2011) Gastric bypass reduces fat intake and preference. Am J Physiol Regul Integr Comp Physiol 301:R1057-R1066

18. Mathes CM, Bueter M, Smith KR, Lutz TA, Le Roux CW, Spector AC (2011) Roux-en-Y Gastric bypass in rats increases sucrose taste-related motivated behavior independent of 
pharmacological GLP-1-receptor modulation. Am J Physiol Regul Integr Comp Physiol 302(6):R751-R67

19. Shin AC, Zheng H, Pistell PJ, Berthoud HR (2010) Roux-en-Y gastric bypass surgery changes food reward in rats. Int $\mathrm{J}$ Obes Lond 35(5):642-651

20. Shin AC, Townsend RL, Patterson LM, Berthoud HR (2011) "Liking" and "wanting" of sweet and oily food stimuli as affected by high-fat diet-induced obesity, weight loss, leptin, and genetic predisposition. Am J Physiol Regul Integr Comp Physiol 301(5):R1267-R1280

21. Hariri N, Thibault L (2010) High-fat diet-induced obesity in animal models. Nutr Res Rev 23:270-299
22. Bueter M, Lowenstein C, Ashrafian H, Hillebrand J, Bloom SR, Olbers T, Lutz T, le Roux CW (2010) Vagal-sparing surgical technique but not stoma size affects body weight loss in rodent model of gastric bypass. Obes Surg 20:616-622

23. Siegel S (1974) Flavor preexposure and "learned safety". J Comp Physiol Psychol 87:1073-1082

24. Bueter M, Lowenstein C, Olbers T, Wang M, Cluny NL, Bloom SR, Sharkey KA, Lutz TA, le Roux CW (2010) Gastric bypass increases energy expenditure in rats. Gastroenterology 138:1845-1853 